\title{
Acopio y comercialización de chía en el municipio de Jalapa, Nueva Segovia por parte de la empresa Central American Commodities Trading en el ciclo productivo 2013-2014 ${ }^{1}$
}

\author{
Jerling Damarys Mendoza² \\ Kasandra Jubelky Arróliga ${ }^{3}$ \\ Tania Rafaela Hernández ${ }^{4}$ \\ Beverly Castillo Herrera ${ }^{5}$
}

\section{RESUMEN}

El presente trabajo se enfoca en el proceso de acopio y comercialización de chía en la empresa Central American Commodities Trading proponiendo estrategias empresariales que mejoren este proceso. Según el nivel de conocimiento es una investigación aplicada y según el enfoque filosófico es una investigación cualitativa. El universo de estudio lo constituye la empresa CAC Trading con sede central en la ciudad de Managua y sucursales en los municipios de Sébaco, Matagalpa, Jalapa, Jícaro y Wiwilí. Las técnicas de recolección de datos son entrevista, observación, investigación documental. Las entrevistas fueron aplicadas a personas con conocimientos desarrollados en acopio y comercialización, asistencia técnica y exportación. Los principales resultados reflejan el proceso de acopio desde el punto de vista de empresa y los productores, sistema de pesaje, principales compradores en la exportación.

Palabras claves: Acopio, comercialización, chía, ciclo productivo.

Recibido: 15 de diciembre de 2014

Aceptado: 22 de junio de 2015

1 Este artículo se elabora a partir de la tesis titulada Acopio y comercialización de chía en el municipio de Jalapa, Nueva Segovia por parte de la empresa Central American Commodities Trading en el ciclo productivo 2013-2014. Para optar al título de administración de empresas en el año 2014 por la UNAN- MANAGUA, FAREM-ESTELI.

2 UNAN-Managua, FAREM-Estelí. Correo Electrónico: jerlingmendoza24@yahoo.com

3 UNAN-Managua,FAREM-Estelí. Correo Electrónico: karroligacenteno@yahoo.com

4 UNAN-Managua, FAREM-Estelí. Correo Electrónico: tania.hernandez85@hotmail.com

5 Candidata a doctora en Ciencias Sociales por la Universidad del Zulia. Maestría en Ciencias Sociales por la Universidad de Guadalajara. Docente titular de la UNAN-Managua, FAREM-Estelí. Correo Electrónico:

beverly.castillo@yahoo.com. 


\title{
Storage and marketing of chia in the town of Jalapa, Nueva Segovia by the Central American Commodities Trading company in the production cycle 2013-2014
}

\begin{abstract}
This paper focuses on the process of gathering and marketing of chia in the Central American Commodities Trading company, proposing business strategies to improve this process. Depending on the level of knowledge this is applied research and according to the philosophical approach is a qualitative research. The universe of study is formed by the CAC Trading Company headquartered in the city of Managua and with branches in the municipalities of Sébaco, Matagalpa, Jalapa, Jícaro and Wiwilí. The data collection techniques are interview, observation, and document research. Interviews were applied to people with knowledge developed in storage and marketing, technical assistance and export. The main results reflect the collection process from the point of view of business and producers, weighing system, and main export buyers in exportation.
\end{abstract}

Keywords: Gathering, marketing, chia, production cycle. 


\section{INTRODUCCIÓN}

La empresa Central American Commodities Trading (CAC Trading) opera en el país desde el 2009, dedicado a la exportación, compra-venta internacional y local de granos básicos y chía. A partir del año 2013 esta empresa ejecuta programas del cultivo de chía, según estudios de APEN es considerado el más grande y completo a nivel centroamericano, incluye financiamiento a los productores entrega de semilla, agro insumos, asistencia técnica y un contrato de compra que garantiza que al concluir su cosecha el producto será comprado.

La empresa CAC Trading con la implementación del cultivo de chía busca alternativas para mejorar las condiciones de vida de los productores ya que sus cosechas son de poco margen y de alto riesgo climático y con esta tiene un mercado seguro. La empresa no cuenta con un buen sistema de pesaje ya que lo hacen de manera tradicional con pesas particulares las cuales no son las adecuadas y que generó conflictos y malos entendidos con los productores ya que perdieron la confianza que tenían hacia la empresa.

La empresa no tiene bodegas de acopio cerca del lugar lo cual ocasiona problemas en el producto al no poseer la calidad adecuada para la exportación. El traslado desde las comunidades hasta los principales centros de acopio genera un gasto más.

Las estrategias que esta empresa utiliza para canalizar recursos es a través de alianzas con cooperativa de crédito en el caso del municipio de Jalapa se trabajó con Fundación para el desarrollo socioeconómico rural (Fundeser) para brindar los recursos necesarios a los productores y estos puedan cosechar.

En la parte de comercialización la empresa no estableció contrato formal de compra con los productores y les incumplió ya que le pagaron un precio de plaza y no el acordado. Otro factor que influye en el proceso de comercialización de chía es el impacto de los precios del producto en el mercado, los cuales son cambiantes debido a las diferentes situaciones climáticas o de sobreproducción lo que conlleva que los productores presenten un déficit al momento de concluir el ciclo del cultivo.

Para exportar chía de alta calidad, CAC Trading trabaja con los productores en un programa de certificación, pero no todos tienen la capacidad de producir bajo este proceso porque tienen que cumplir con requisitos para garantizar la calidad y sostenibilidad en el cultivo, entre ellos: implementar los requerimientos de la carta tecnológica, buenas prácticas agrícolas, conservar la higiene en el cultivo, llevar registro de cada actividad.

El objetivo principal del estudio es analizar el proceso de acopio y comercialización de chía que utiliza la empresa Central American Commodities Trading y los productores en el municipio de Jalapa, Nueva Segovia ciclo productivo 2013-2014, proponiendo estrategias empresariales que mejoren este proceso.

\section{MATERIALES Y MÉTODOS}

Según el nivel de conocimiento esta es una investigación aplicada porque se va a analizar el proceso de acopio y comercialización de chía en el municipio de Jalapa Nueva Segovia por la empresa CAC Trading y se propondrán estrategias empresariales para que la empresa mejore.

El muestreo es No probabilístico, porque no todo el universo tiene la misma probabilidad de ser seleccionado. Para determinar la muestra se definieron los siguientes criterios: 1)Disposición de los informantes claves a ser entrevistados y participación voluntaria en el estudio 2) Informantes claves en la empresa, con conocimientos desarrollados en acopio y comercialización, asistencia técnica y exportación 3 ) Pequeños productores que trabajan con CAC Trading en este ciclo productivo. 
Para el cumplimiento de objetivos planteados se utilizaron las técnicas de recolección de datos como investigación documental, entrevista, guía de observación.

\section{Conceptos técnicos del estudio}

En esta investigación se han identificado cuatros ejes teóricos que son: Empresa, acopio, comercialización y exportación.

Según Chiavenato (2001) la empresa son ciertas clases de organizaciones o unidades sociales que buscan a alcanzar objetivos específicos, y su razón de ser es cumplirlos. Acopio es un espacio, que tiene como fin la reunión o recolección de productos en grandes cantidades para luego poder almacenarlo por un tiempo definido y así poderlo comercializar y distribuir en ventas o mercados en las mejores condiciones posibles. (Pag.8)

\section{Importancia de empresa}

La importancia de una empresa radica en inculcar los valores a los propios empleados de forma que dichos valores afecten a las relaciones que se mantienen con los clientes. Estos valores o formas de comportarse pueden parecer prioridad como obligaciones, son imposiciones de la empresa hacia sus empleados.

En ocasiones no se entiende la política empresarial ni se sabe porque se toman las medidas que se toman. Muchas veces los empleados deben de vestir con ropas determinadas, realizar llamadas siempre de la misma forma, evitando decir ciertas palabras o despidiéndose siempre de la misma manera. Estas formas son las que a largo plazo van a influir y dar importancia a la empresa.

Algunas empresas tienen a los clientes como la prioridad número uno en importancia. Dicha empresa crea una política clara y una cultura hacia el cliente potencial de manera que el cliente lo entienda y lo valore. Casi siempre esta política afectara al empleado, que será en última instancia quien la adopte y la exponga directamente al cliente.

La comercialización es un conjunto de acciones encaminadas a comercializar productos. Las técnicas de comercialización abarcan todos los procedimientos y manera de trabajar para introducir eficazmente los productos en un sistema de distribución (Kotler, 1989, P.75). Se tomó en cuenta este concepto técnico ya que la empresa pretende crear canales o vínculos de comercialización sin tener que recurrir a terceros.

\section{Comercialización agrícola}

La comercialización agrícola cubre los servicios que se ocupan de hacer llegar el producto desde el punto de cosecha al consumidor. Las condiciones productivas constituyen el elemento más dinámico de la producción.

La Exportación es una venta que se realiza más allá de las fronteras arancelarias en la que está situada la empresa. Exportar es vender y solo vender, la misma tecnología utilizada para la venta debe ser utilizada para exportar. (Mercado, 1996 P. 26).

La forma más sencilla para entrar al mercado extranjero es mediante la exportación ocasional es un nivel pasivo de intervención donde la firma exporta excedentes de cuando en cuando, y vende bienes a compradores residentes que representan a firmas extranjeras. La exportación activa ocurre cuando la compañía hace un compromiso para ampliar las exportaciones a un mercado particular.

\section{RESULTADO Y DISCUSIÓN}

Central American Commodities Trading (CAC Trading), surge a partir de una conversación de dos amigos que se decidieron trabajar por cuenta propia, uno de ellos era gerente general de Cisa Agro internacional, el otro era miembro de la cámara de comercio y tenía los contactos locales e internacional para comercializar, iniciaron con su proyecto de crear 
una empresa y dejar su campo de comodidad, tenía un trabajo estable salieron al mercado a iniciar su aventura de implementar la idea de crear una empresa.

Es una empresa que fue constituida el 25 de febrero de 2009, como una empresa dedicada a la unión de mercados, entre Norte y Centro América, con los mercados de pequeños productores de Nicaragua. Sus oficinas principales están en Managua, Nicaragua. Sin embargo exporta a Canadá, Estados Unidos, y Centro América.

Sus clientes principales son la industria alimenticia, institucional y re-exportadores de otros países del área así como también distribuidores de productos centroamericanos en los Estados Unidos y resto del mundo que llevan el inconfundible sabor de las comidas a la mesa. La empresa inicio con un capital propio nicaragüense y después ellos buscaron alternativas para atraer inversionistas internacionales. En los últimos años el capital de CAC Trading tiene una inversión internacional de países Árabes Estados Unidos y Canadá.

La misión de esta empresa es la satisfacción completa de nuestros clientes tanto locales como internacionales como consecuencia de que le podamos suplir Commodities o productos de alta calidad a precios competitivo.

La visión de la empresa a mediano plazo es ser la primera opción comercial de clientes locales como internacionales para proveerse de frijol rojo seda, Cacao en grano seco, maíz, semillas de chía y otros.

Los valores que posee esta empresa son: Responsabilidad: Cumplir con los acuerdos y convenios que realiza la empresa con los pequeños productores y cooperativas que brindan financiamiento.

- Integridad: Actuar con rectitud y honestidad en las actividades que se desempeñan dentro y fuera de la empresa.

- Lealtad Eficiencia y excelencia: Brindar lo mejor posible en el momento requerido.

- Constancia: Mantenerse en la búsqueda de la mejora continua para hacer mejor lo que se hace bien.

- Desarrollo personal: Crecimiento personal y profesional de nuestro equipo que beneficie tanto a ellos como a la empresa.

\section{Estructura organizativa de CAC Trading}

La estructura organizativa de CAC Trading presenta como nivel jerárquico más alto a la Dirección General y cuenta con tres departamentos encargado de velar por su bienestar y hacer cumplir con los objetivos: Gerencia General Comercio Internacional.

Las operaciones de la empresa se dividen en tres áreas: Área de Finanza, Área de Acopios, Área Técnica donde se realizarán las actividades principales de la empresa. En el área de Finanzas se llevan todos los registros y operaciones contables, la base de datos y los contratos con los pequeños productores. En Acopio la empresa almacena el producto y le da mantenimiento para garantizar los estándares de calidad que exigen los compradores internacionales.

Además la empresa presta servicios de asesoría técnica a los diferentes productores que trabajan con granos básicos que se producen en nuestro país y a la compraventa de estos granos. 


\section{Grafico $\mathrm{N}^{0}$ 1: Estructura organizativa de CAC Trading}

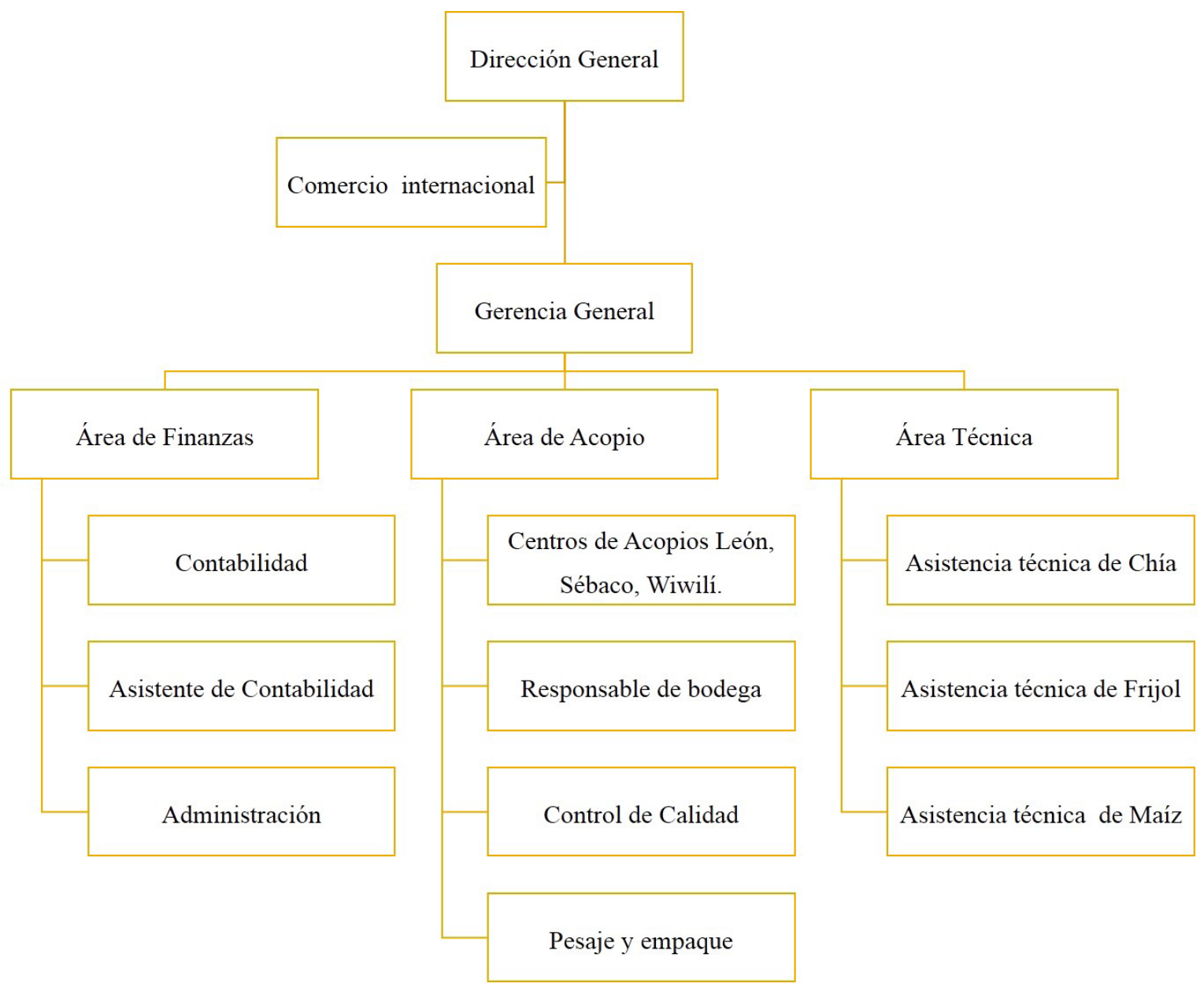

\section{Requisitos para trabajar con CAC Trading}

Los productores que trabajan con CAC Trading deben estar solventes con las financieras y cooperativas con las cuales tiene alianza de financiamiento la empresa para obtener los recursos necesarios para su producción entre ellos tienen insumos, semillas de calidad, asistencia técnica todo con el propósito de obtener un producto final de calidad.
La empresa también utiliza la central de riesgos para verificar los record crediticios y los productores tienen que ser responsable ya que la empresa lo que pone en garantía es la comercialización es decir se compromete a comprar el producto.

Las cooperativas y Financieras que forman parte del programa que promueve la empresa no solicitan prenda en garantías. 


\section{Descripción general del proceso de producción de chía.}

\section{Grafico No 2: Proceso de producción del cultivo de chía.}

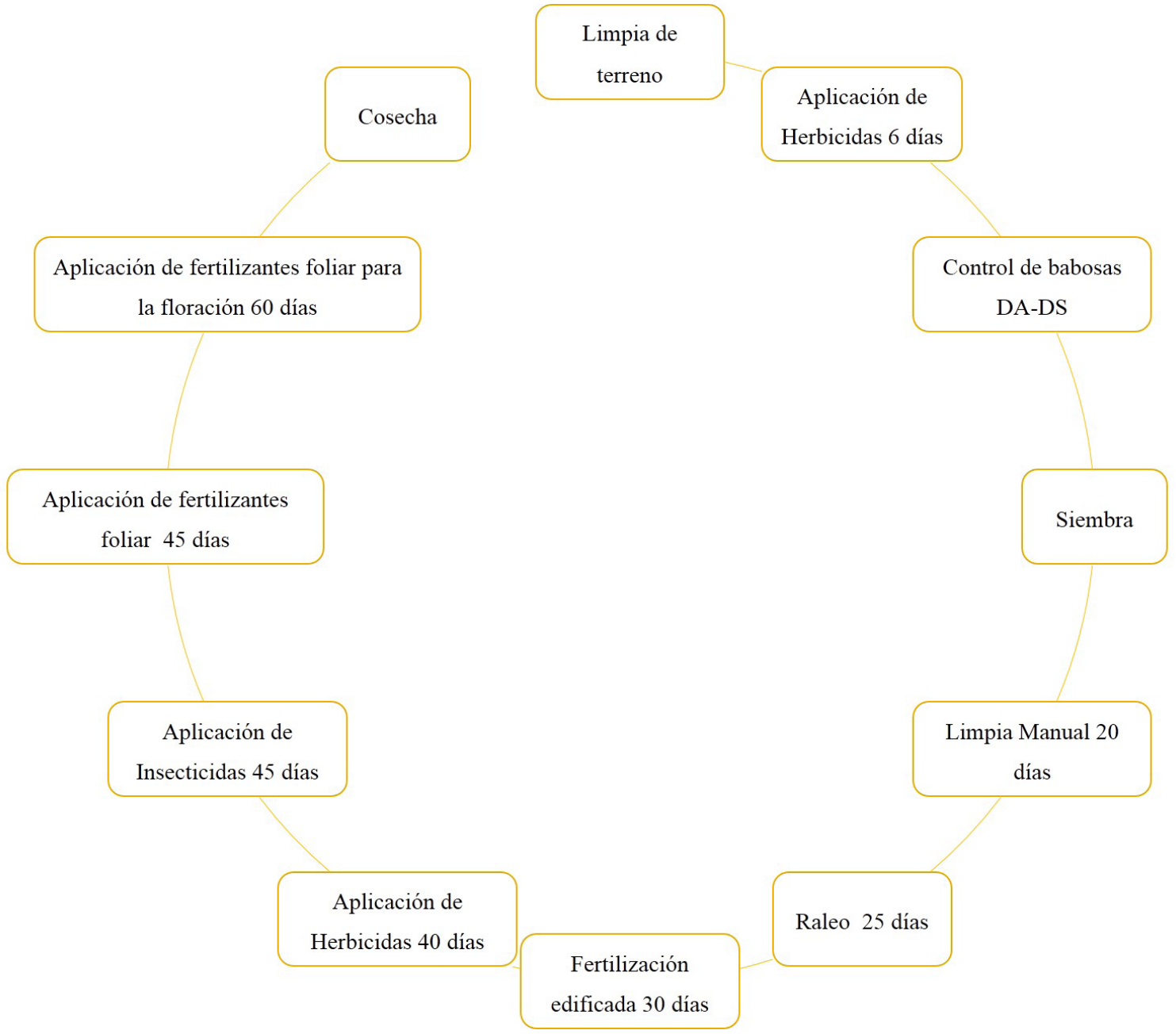

La chía (Salvia hispánica L) es una planta herbácea, es una de las especies vegetales conocidas hasta en el año 2006. Se cultiva por ello para aprovechar sus semillas, que se utilizan molidas como alimento.

La semilla de chía contiene muchas propiedades como: proteína, calcio, boro (mineral que ayuda a fijar el calcio de los huesos), potasio, antioxidantes, hierro, ácidos grasos como omega 3 y vitaminas tales como magnesio, manganeso, cobre, niacina, zinc entre otras.

Este cultivo prefiere suelos ligeros a medios, bien drenados, no demasiado húmedos; como la mayoría de las salvias, es tolerante respecto a la acidez y a la sequía, pero no soporta las heladas. Requiere abundante sol, y no fructifica en la sombra.

Proporciona energía, aumenta fuerza y resistencia: por sus altos contenidos de proteínas y la combinación de vitaminas y minerales nos ayudan a ser constantes a nuestras actividades diarias.

Eso la convirtió en los últimos años en la materia prima favorita de la industria alimenticia y farmacéutica, principalmente en Estados Unidos y Europa, donde cada vez más personas se unen a la búsqueda de alimentos funcionales que garanticen una vida sana. 
La empresa ejecuta el programa de chía en los municipios de Jícaro, Murra, Jalapa-Nueva Segovia, Quilalí Yalí y Wiwilí-Jinotega logro acopiar seis mil ochocientos quintales, donde el municipio de Jalapa fue el más productivo.

La carta tecnológica consiste en el seguimiento que se les da a los productores la cual la aplican y conforme a ello se le da seguimiento al cultivo, esta carta tecnológica le sirve desde el inicio hasta al final del ciclo productivo. El ingeniero Peralta manifestó la carta tecnológica incluye la ficha técnica y costos estimados en base a otros estudios con el propósito de establecer las normativas de gastos para cada cultivo o producción, planificar el tiempo necesario antes y después de sembrar la semilla.

Los productores expresaron que trabajan con CAC Trading porque consideran que es un programa interesante ya que es un cultivo nuevo en el municipio y que pueden tener un gran margen de ganancia ya que sus terrenos son aptos para cultivar chía. Para el desarrollo de la asesoría técnica la empresa CAC Trading trabajo con noventa productores que fueron atendidos por dos técnicos: el Ingeniero Alan Samuel Peralta y el Ingeniero Erling Oniel Montiel.

La principal dificultad fue la asesoría técnica porque a veces los técnicos les decían que llegarían en un fecha determinada a darle seguimiento al proceso y no llegaban lo que provocó afectación al cultivo por algunas enfermedades y que no se desarrollara bien la planta, por ende afectó el resultado de la producción.

El productor Jaime Roberto Pozo de la comunidad la Luz Terrerio manifestó su satisfacción de haber trabajado con esta empresa ya que este rubro es nuevo en el país, es un producto no tradicional contribuye en la economía de los pequeños productores. Este productor sembró tres manzanas, invirtió setenta mil córdobas (C\$ 70,000.00), obtuvo doce quintales por manzana y la empresa le pago seis mil quinientos córdobas (C\$
$6,500.00)$ por quintal obteniendo ingresos por ciento sesenta y dos mil córdobas (C\$162,000.00) y una ganancia de noventa y dos mil córdobas $(\mathrm{C} \$ 92,000)$ la ganancia se reinvirtió en la mejora de su finca para que sus tierras sean más productivas.

\section{Proceso de acopio}

Para el proceso de acopio la empresa utiliza unidades de acopio en las comunidades, establecen convenio verbal con uno de los productores para acopiar en la zona, al cual se le desembolsa una determinada cantidad de dinero, se le paga una comisión por quintal acopiado y también se utiliza la estrategia de ir a comprar el producto directamente al productor y lo trasladan a los centros de los acopios ubicados en Sébaco, León y Wiwilí. La finalidad del acopio es comprar a un buen precio y vender a un buen precio y el productor se ahorra el uso de intermediarios.

Los problemas más comunes que presentaron los productores en el proceso de acopio son el transporte y la distancia de sus parcelas para el traslado del producto.

Las ventajas que tienen los productores al acopiar con esta empresa es que compro su producto, no utiliza intermediario por que el objetivo de la empresa es obtener ganancias y que los productores obtengan sus propias ganancias.

Con respecto a las mejoras del acopio hasta el momento se trabaja bien porque no son acopios fijos sino temporales para no incurrir en más gastos a los productores, la empresa tiene acopios grandes dependiendo del volumen de producción.

Con la implementación de silos y bodegas se garantiza las condiciones adecuadas para almacenar los granos acopiados durante el ciclo productivo. Los centros de acopio CAC Trading brindan los servicios de recepción, limpieza, secado, almacenamiento, fumigación, conservación, empaque, pesaje y despacho de granos. 
Cuentan con limpiadoras de granos con las cuales pueden reducir, en un alto porcentaje, el contenido de finos y gruesos, según sea la necesidad del cliente. Este servicio puede prestarse antes, durante o después del almacenamiento. Tiene la capacidad de almacenamiento de 900 mil quintales de granos, de los cuales 500 mil pueden ser almacenados en los silos y 400 mil en las bodegas.

\section{Sistema de pesaje}

La empresa estableció en el municipio de Jalapa centros de acopios temporales donde se desarrolló el sistema de pesaje que se llevó a cabo con ayuda de los productores, el encargado del acopio y el responsable de comercialización. Esta es la parte delicada donde el operador debe asegurarse que el producto es apto para la venta y cumple las normas de calidad del mercado. Cuando se procede al almacenamiento, se debe pesar cada saco y anotar su peso bien claro en el centro.

\section{Traslado al centro de acopio}

El sistema de traslado al centro de acopio debe ser tan económico y eficaz como sea posible. La empresa tiene una planificación rigurosa de la utilización de los vehículos, en función de las prioridades de transporte de ciertos productos, del respeto de ciertos horarios y de la disponibilidad de personal.

Para una buena planificación de los transportes, hay que tener en cuenta la situación de los puntos de acopios y almacenamiento, así como las distancias que los separan y las cantidades de productos que han de cargarse o descargarse en cada punto.

Actualmente la empresa ha realizado una inversión en el sistema de transporte de granos, para evitar retrasos al momento de la recepción del producto, lo que permite incrementar los niveles de operación en todos los sectores.

Los productores llevan con frecuencia su producto en pequeñas cantidades por caminos muy malos o senderos. El tiempo de transporte es así considerable $\mathrm{y}$ el costo por unidad de producto transportado es elevado, lo que supone una reducción sustancial de los ingresos y no estimula a los productores para aumentar su producción.

Para que crezca la producción es preciso que la empresa y los pequeños productores desarrollen estructuras de almacenamiento, en función de mejorar las necesidades del transporte de los productos.

\section{Precio de compra}

En el año 2012 el precio de la chía fue de dieciocho mil córdobas (C\$18000) por quintal, en los últimos meses del 2013 pasó a dos mil trecientos y dos mil quinientos córdobas (C\$2300 y C\$2500) valor que se mantiene hasta la fecha.

CAC Trading con los productores firmaron un contrato de compra-venta en la cuales se establecían un precio mínimo de compra que era de cuatro mil córdobas $(C \$ 4,000.00)$ por quintal. En el caso del municipio de Jalapa la empresa no estableció ningún precio sino que el precio que pagarían era un precio a plaza es decir al precio de mercado que fue un equivalente a dos mil quinientos córdobas $(\mathrm{C} \$ 2,500.00)$ por quintal.

En algunos casos los productores no quisieron entregarle su producto a la empresa por lo que decidieron comercializarlo en el mercado del municipio de Jalapa con los compradores locales esperando obtener un mejor precio, no sucedió lo que esperaban ya que lo vendieron al mismo precio que les ofrecía la empresa e incurrieron en los gastos de traslado.

\section{Principales compradores en la exportación}

La empresa para comercializar el producto a nivel internacional establece alianzas de comercialización ya que no busca directamente a los posibles compradores sino que lo hace a través de la Asociación de Productores y Exportadores de Nicaragua (APEN), por medio de internet aprovechando al máximo la 
tecnología y también participan en los programa del Centro de Exportaciones e Importaciones (CEI) y visita a los clientes en los principales mercado de CAC Trading.

La debilidad que la empresa tiene es el mercado inestable ya que el precio del producto puede aumentar o disminuir, frente a esa debilidad tiene una fortaleza ya que la empresa no trabaja con un solo producto sino más bien con varios es decir que si hoy el precio de un producto disminuye y aumenta el precio de otro de los productos de la cuales ellos comercializan hacen frente a la situación con ese producto.

CAC Trading envía granos a Estados Unidos a nueve estados que incluyen Texas, New Jersey, Washington, Florida, Maryland, Nueva York, Atlanta y California y a Centroamérica a El Salvador, Costa Rica, Guatemala y Panamá. El catálogo de su página web www. CACTrading u.s, muestra los diferentes productos nicaragüenses que llegan a suelo norteamericano, directo, desde el productor. La licenciada Calero comento:

"Por la cercanía con los agricultores y asociaciones de productores contribuye a reducir la cadena de intermediación comercial, lo que los hace más competitivos tanto en precio como en calidad... APEN y CEI nos ha apoyado desde un inicio para poder exportar. La idea con CAC Trading nació para ir capturando el mercado en los Estados Unidos y fue asi que decidieron poner una planta procesadora cerca de las fuentes productivas, en una relación directa con productores y cooperativas. Después vino el proceso de buscar los clientes en los Estados Unidos, visitando ferias, trabajando duro."

\section{APEN como exportadora de CAC Trading}

La Asociación de Productores y Exportadores de Productos de Nicaragua (APEN) es una organización privada, sin fines de lucro, con más de 20 años trabajando por el fortalecimiento y la promoción exportadora de Nicaragua, a favor del desarrollo económico del país.

Es líder del sector productivo-exportador, transformando a Nicaragua en una nación exportadora. Facilitan a productores y exportadores, el máximo aprovechamiento de las oportunidades que ofrecen los mercados internacionales, impulsando los nuevos factores de competitividad empresarial, mediante servicios de capacitación y asistencia técnica, asesoría, información comercial, participación en ferias internacionales, misiones comerciales, ruedas de negocios directas e inversas.

Su misión es apoyar a los pequeños, medianos y grandes productores y exportadores ante las organizaciones internacionales e instituciones nacionales en aspectos de interés de los sectores así como apoyar y brindar servicios para optimizar la cadena productiva, mejorar la competitividad y la capacidad exportadora del país para lograr mayores ventajas en los mercados regionales e internacionales.

Comisiones conformadas:

- Arte Textil, Cuero y Accesorios de Moda (CONIMODA)Frijol

- Raíces y Tubérculos

- Hortalizas

- Plátano

- Chía

- Café

- Tecnología de Información y Comunicaciones (TIC).

Ramsés Ortega gerente general de CAC Trading manifestó: "La alianza con APEN surge a partir de participación en ferias y encuentros con fundadores de la asociación trabajan en conjunto con APEN desde hace cinco años, con el propósito de explotar las opciones de mercados que esta asociación les ofrece a las pequeñas, medianas y grandes empresas nicaragüenses en desarrollo para mejorar su competitividad". 
CAC Trading para el año 2013 exporto 60 toneladas de chía a un costo de ciento ochenta un mil trecientos córdobas (C\$181,300.00) cada tonelada. En el transcurso de este año la empresa ha exportado 400 toneladas a un costo de ciento cuarenta mil doscientos cincuenta córdobas (C\$ 140,250.00).

CAC Trading en el año 2013 logro obtener en sus exportaciones una utilidad de dos millones ciento treinta mil con cuarenta y siete centavos córdobas (C\$ 2, 130,000.00). En el transcurso del año 2014 sus exportaciones una utilidad de treinta y cuatro millones novecientos ochenta mil córdobas (C\$34, 980,000.00). El precio de este producto en el mercado internacional ha tenido una disminución.

Proceso de comercialización entre CAC Trading y APEN.

Acontinuaciónsemuestraelprocesodecomercialización que utiliza la empresa para comercializar sus productos en el mercado nacional.

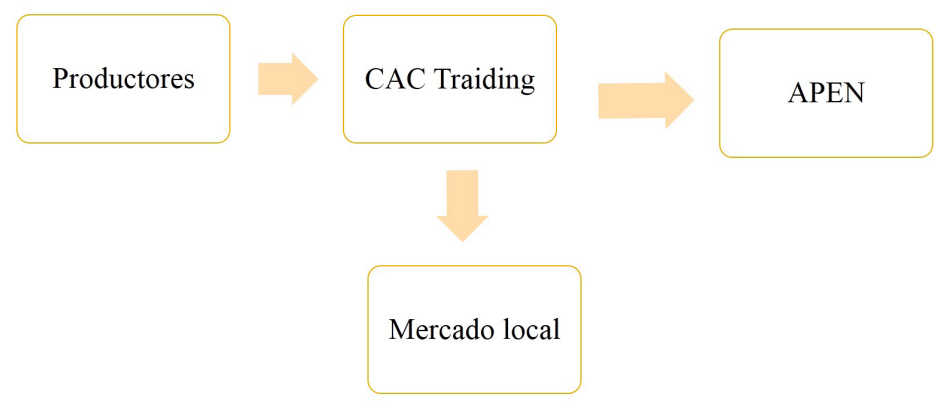

Estrategias de comercialización que utiliza APEN para canalizar compradores internacionales.

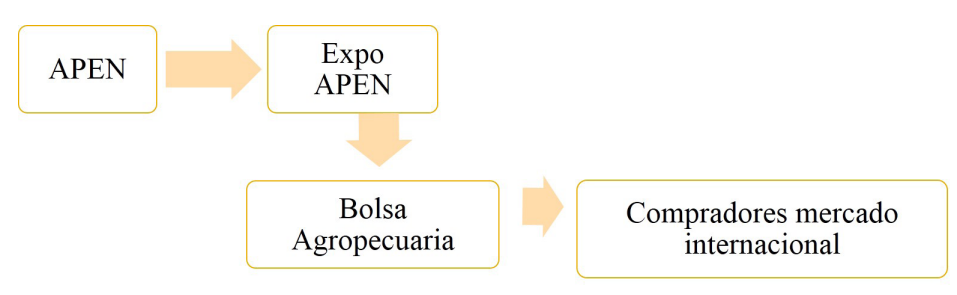

Criterios de calidad que exige APEN para exportar Los criterios para exportar que debe poseer el producto son: Los parámetros de calidad que exige el mercado internacional, certificado sanitario y fitosanitario ya que es un producto agrícola lo que exportan, cumplir con todos los estándares que establece el comprador internacional, cumplir con todos los parámetros de calidad que existe en cada país, saber diferenciar y conocer el mercado al cual están exportando.

\section{Requisitos para exportar}

Los requisitos para exportar para iniciar tienen que estar constituida como empresa:

- Fotocopia de RUC.

- Constancia de contribuyente en la DGI.

- Registros de firma.

- Registro en el CETREX.

- Licencia de exportador.

- Solvencia Fiscal

- Poder general de administración debidamente inscrito en el registro mercantil.

- Formulario Declaración de Mercancías de Exportación.

- Factura de exportación.

- Constancia de certificación fitosanitaria emitida por los servicios regionales del MAGFOR

Esta debe de cumplir con las normas técnicas obligatorias para la producción y comercialización de semillas certificadas de granos básicos y soya.

Cuando CAC Trading tiene una demanda de cierta cantidad de chía por parte del cliente elabora un plan de acuerdo a la venta que se pretenden hacer, este es realizado por el responsable de comercialización.

La muestra se solicita al responsables de los acopios para enviárselo a los clientes para su observación y aprobación. 
La empresa puede captar posibles compradores a través de la tecnología y se establecen los parámetros que comprende el contrato de compra-venta. En el contrato se define cuantos sacos se van exportar, la calidad de la chía, la fecha para cual lo quiere el cliente (Cesar Laguna).

Para elaborar facturas proformas el área de contabilidad y finanzas se encarga de actualizar los precios de la chía y ellos se encargan de establecer el precio para determinado contrato y con ese precio se factura.

Certificación fitosanitaria emitida por el MAGFOR el cual se obtiene enviando una muestra de chía. Esta certificación debe tener el sello del MAGFOR. La certificación de calidad se inspecciona durante la recepción, almacenamiento y el despacho del grano. El cliente es informado periódicamente sobre las condiciones de calidad de sus granos.

\section{Precio de mercado internacional}

La empresa maneja un precio de venta de ciento setenta dólares (U\$ 170.00) a nivel internacional equivalentes a cuatro mil trescientos treinta y cinco córdobas ya que se dedica a exportar el producto. Con este precio han decidido no vender ya que ellos compraron el producto a cuatro mil córdobas (C\$ 4,000.00) por quintal manteniendo el producto en los acopios y esperar que el precio se supere para poder comercializar.

El impacto mayor ha sido en el mercado internacional, donde el precio ha tenido un descenso de alrededor de un treinta y nueve por ciento, ya que de llegarse a pagar a doscientos ochenta dólares (US\$280) por quintal, en el mercado estadounidense, actualmente se paga a ciento setenta dólares (US\$170).

Según la Lic. Calero, CAC-Trading pagaba en el año 2013 precios entre seis mil y seis mil ochocientos córdobas (C\$ 6,000.00 y C\$ 6,800.00) por quintal a los productores, y al inicio del presente año, les pagó hasta cinco mil cuatrocientos córdobas $(\mathrm{C} \$ 5,400.00)$. La empresa tiene contratos firmados con los productores del municipio de Jalapa con un precio mínimo de cuatro mil córdobas (C\$ 4,000.00).

Los precios bajan, debido a las cosechas de países como Argentina, Bolivia y Perú. Calero agregó a México entre esos países donde su producción es diferente a Nicaragua.

\section{Principales limitantes del proceso de comercialización}

El sistema que utiliza en el país las entidades gubernamentales ya que viven cambiando constantemente las leyes de ingresos y de concertación tributaria y los trabajadores del estado no la dominan bien.

En Nicaragua hay un régimen fiscal pro exportador, las leyes no son malas. El problema se da en la ejecución de las leyes. Los beneficios de las leyes fiscales no requieren mejorías en sí, requieren mejorías en su concreción. Es necesario dinamizar el papel de la Comisión Tributaria Interinstitucional.

- Ineficacia de la DGI la empresa paga los impuestos en tiempo y forma y al momento que quiere realizar una transacción de exportación le sale que no tiene algunas solvencias.

- Ineficiencia de DGA ya que retrasan papeles lo cual conlleva gastos y pérdida de tiempo.

- Baja producción en los productos.

\section{Análisis de matriz FODA en función del Acopio}

A partir de los resultados de la presente investigación se identificaron las principales Fortalezas, Oportunidades, Debilidades y Amenazas de CAC Trading. A partir de este análisis se proponen estrategias para mejorar el proceso de Acopio de dicha empresa.

Fortalezas: 1) Productores que acopian su producto con CAC Trading. 2) Transporte para trasladar el 
producto de las comunidades a los acopios principales. 3) Estricto control de calidad.

Oportunidades: 1) Productores dispuestos a trabajar con la empresa. 2) Posicionamiento en el mercado. 3) Crecimiento de la demanda del producto.

Debilidades:1) Poco tiempo trabajando con este rubro. 2) Obsoleto sistema de pesaje. 3) No se cuenta con instalaciones adecuadas para llevar a cabo el proceso de acopio.

Amenazas: 1) Disminución de la producción y calidad por las condiciones climáticas. 2) Competencia. 3) Condiciones de mercado cambiantes

\section{Estrategia FO}

$\mathbf{E}_{1:}$ Mejorar las relaciones con los productores actuales que a su vez generan la captación de productores potenciales para este rubro $(\mathrm{F} 1, \mathrm{O} 1)$.

\section{Estrategia DO}

$\mathbf{E}_{1}$ : Ofrecer asistencia técnica para fortalecer la relación proveedor- empresa logrando mantener la cooperación mutua (D3, O1)

\section{Estrategia FA}

$\mathbf{E}_{\mathbf{1}}$ : Incentivar a los productores que trabajen con los programas establecidos por CAC Trading, lo cual permitirá acceder a mercados internacionales (F3, A2).

\section{Estrategia DA}

$\mathbf{E}_{1}$ : Mejorar el sistema de pesaje que utiliza la empresa CAC Trading (D2, A2).

$\mathbf{E}_{2}$ : Invertir en un centro de acopio que preste la condiciones para la recepción y almacenamiento del producto (D3, A2).
Análisis de matriz FODA en función de la comercialización.

Fortalezas:1) Compradores internacionales que demandan el producto. 2) Alianza con empresas que exportan granos. 3) Ofrecen un producto certificado

Oportunidades:1) Precios diferenciados para la chía tecnificada. 2) Posicionamiento en el mercado internacional.3) Recursos económicos disponibles para comprar el producto.

Debilidades:1) No posen una buena organización de distribución. 2) Atrasos al sacar el producto a mercados internacionales debido a procedimientos de régimen fiscal.

Amenazas: 1) Variaciones que se pueden presentar con respecto a la demanda. 2) Nuevas regímenes fiscales del gobierno. 3) Incremento de la competencia.

\section{Estrategia FO}

E1: Desarrollo de mercados internacionales (F1, F2, $\mathrm{O} 1, \mathrm{O} 2)$.

\section{Estrategia DO}

E1: Mejorar la relación con entes fiscalizadores que permitan la agilización de los procesos de comercialización (D2, O2).

\section{Estrategia DA:}

$\mathbf{E}_{\mathbf{1}}$ : Crear una línea de financiamiento a través de entidades crediticias que permita el mejoramiento de las condiciones de producción (D1, D2, A2).

\section{Propuesta de líneas estratégicas}

Línea 1: Mejorar las relaciones con los productores actuales que a su vez generan la captación de productores potenciales para este rubro. Objetivo: Establecer relaciones laborales entre CAC Trading y productores para recuperar el prestigio y la capacidad de oferta del producto en el mercado. 
Línea 2: Incentivar a los productores que trabajen con los programas establecidos por CAC Trading, lo cual permitirá acceder a mercados internacionales. Objetivo: Motivar a los productores para trabajar en este rubro mejorando la comercialización internacional.

Línea 3: Mejorar el sistema de pesaje que utiliza la empresa CAC Trading. Objetivo: Implementar un sistema de pesaje apropiado para acopiar sus productos.

Línea 4: Desarrollo de mercados internacionales. Objetivo: Buscar nuevos mercados internacionales para comercializar sus productos.

Línea 5: Crear una línea de financiamiento a través de entidades crediticias que permita el mejoramiento de las condiciones de producción. Objetivo: Crear convenios con entidades financieras para apoyar a los pequeños productores miembros de los programas de CAC Trading

\section{CONCLUSIONES}

CAC Trading S.A, es una empresa pionera en ejecutar programa de cultivo y comercialización de chía con el objetivo de convertirlo en un cultivo no tradicional pero tecnificado para aumentar los rendimientos por manzanas y con ello el volumen de exportación.

Las condiciones productivas que deben cumplir los pequeños productores son que sus parcelas presten las condiciones que exige la empresa y trabajar con la carta tecnológica que esta sugiere y los requisitos para tener acceso al financiamiento deben estar solventes con las financieras. La empresa tiene algunos problemas para identificar productores y entidades financieras para que trabajen con el programa, proceso de certificación y plan de financiamiento que esta ejecuta.

En el proceso de acopio y comercialización la empresa tiene una desventaja de no contar con un centro de acopio en el municipio de Jalapa que preste las condiciones para almacenar el producto. La empresa ofreció un precio de compra de manera verbal a los productores pero al momento de realizar el proceso de compra la empresa no pago lo estipulado.

La calidad de la chía depende de las condiciones climáticas, implementación de los requerimientos de la carta tecnológica, buenas prácticas agrícolas, conservar la higiene en el cultivo, llevar registro de cada actividad.

\section{RECOMENDACIONES}

\section{A la empresa:}

1. Aprovechar el programa que ejecuta para el cultivo de chía ya que es considerado el más grande y completo a nivel centroamericano ya que incluye financiamiento y sobre todo comprometerse con los productores y garantizarle los recursos necesarios para que desarrollen su proceso productivo e incidan en la economía familiar.

2. Motivar a los productores de granos básicos convencionales para que se integren en el programa y vean la chía como un cultivo alternativo por considerarse un producto más rentable, de esta manera lograr aumentar el número de exportaciones de chía de calidad y tener acceso a nuevos mercados.

3. Es necesario que la empresa mejore las estrategias de financiamiento para los productores, las relaciones con los productores, se recomiendan que establezcan estrategias y objetivos para mejorar el proceso de acopio y comercialización.

4. Mejorar la misión y visión de la empresa.

\section{A los productores:}

1. Participar en las capacitaciones brindada por la empresa, aplicar los conocimientos adquiridos, cumplir adecuadamente los requisitos e implementar la carta tecnológica que la empresa exige y las recomendaciones de los encargados 
de la asistencia técnica para garantizar un buen cultivo, productividad y equilibrio económico.

2. Exigir un contrato formal y completo que establezca las condiciones de trabajo, precio de compra del producto y que su principal objeto sea respaldar el financiamiento ante entidades financieras.

3. Productores de granos básicos convencionales que tomen la iniciativa de participar en los programas que ofrece CAC Trading y ver el cultivo de chía como una alternativa rentable.

\section{A la Facultad Regional Multidisciplinaria}

Que continúen formando profesionales de calidad, motivándolos a desenvolverse en un entorno investigativo, diseñando estrategias de relaciones con entidades que se les facilite el proceso de investigación.

\section{BIBLIOGRAFÍA}

Chiavenato, Idalberto (2001). Administración. Teoría, proceso y práctica. Editorial Mac Graw Hill. Tercera Edición. Colombia.

Kotler, Philip (2011). Mercadotecnia Internacional. Editorial McGraw-Hill. Sexta Edición. México.

Kotler, Philip (2011) .Mercadotecnia Ampliada. Editorial McGraw-Hill. Tercera Edición. Pág. 642-644

Instituto de información del gobierno de los municipios (2002). Descripción del municipio de jalapa. [En línea]. Consultado [22, Abril, 2014] Disponible en: http://www.inifom.gob.ni/ municipios/documentos/NUEVA\%20SEGOVIA/ jalapa.pdf 